\title{
Three-dimensional Numerical Simulation for a Spillway Tunnel with High Head and Large Discharge
}

\author{
Zhang hongqing1, 2, Wan wuyi2, Bao zhongjin1, Hu jinchun1, and Ye long1 \\ 1.Zhejiang Institute of Hydraulics \& Estuary, NO.50 Fengqi East Road, Hangzhou,China \\ 2.College of Civil Engineering and Architecture, Zhejiang University, NO.866 Yuhang Road, \\ Hangzhou, China
}

\begin{abstract}
At present, the domestic large-scale water conservancy projects increase in growing number augmenting the amount of the spillway tunnel with high head and big flow, and then the problem of the high speed air flow occur, which cause a series of issues. In order to carry out three-dimensional calculation of hydraulic characteristic of a certain spillway tunnel on the right band of a hydropower station in China, VOF model and turbulent model were used, and discharge capacity , water depth 、 pressure distribution of pressure section、 ventilation characteristics and wind speed distribution are given in this paper, which provide experience for optimizing shape of spillway tunnel. At the same time, a good agreement between numerical model results and test results is obtained.
\end{abstract}

Keywords: Spillway tunnel; Aerated flow; VOF model; $k-\varepsilon$ turbulent model; Model test

\section{Introduction}

The spillway tunnel is always used as flood discharge facility in many water conservancy projects. With the progress and development of the technology, the domestic large-scale water conservancy projects increase in growing number, so the amount of the spillway tunnel with high head and large discharge are augmented. However, this tide also brings a series of highspeed hydraulics problems $[1,4]$. The high speed air flow is one of those problems. Due to the design and layout of the project, flood discharge tunnel in actual operation will induce the high-speed airflow within buildings such as the wind tunnel of the working gate and the air hole of bulkhead gate, causing that the loud noise in the entrance of the wind tunnel、 hoist room of the working gate and the local failure in the flood-discharge tunnel. Furthermore, wind speed in the spillway tunnel should be lower than $60 \mathrm{~m} / \mathrm{s}$ [5], otherwise the safe operation of the spillway tunnel has been effect. So studying the hydraulic characteristics in the spillway tunnel, even the spillway tunnel with high head and large discharge, is necessary

With the rapid development of the computer technology, numerical simulation has become a significant method to study the water-air two-phase flow in the flood discharge. VOF model [6] has been widely used in the research of aerated flow in the flood discharge as a kind of relatively simple simulation method of two-phase flow. For example, Den etc. [7] combined this model and model to numerically simulate the hydraulic characteristics in spillway tunnel with high head. It was concluded that the volume of ventilated air in the 
ventilation holes of working gate room by simulation was relatively coincided with the measured one; Wang [8] also used the VOF model and model to simulate the corrosion reduction of aerated flow in the spillway tunnel. The results show that v-shaped candy was good at increasing the aerated flow and improving the indexes like the volume of ventilated air

In China, there is a certain spillway tunnel with high head and large discharge, whose total storage is $237.03 \times 108 \mathrm{~m} 3$ and the condition of checking water level. is $817.99 \mathrm{~m}$. So the model and the VOF model are initially combined to numerically calculate the overall of the spillway tunnel on the right band of a hydropower station in this paper. We get discharge capacity water depth 、 pressure distribution of pressure section and non-pressure section and ventilation characteristics. Meanwhile, the results are compared with the test value

\section{Mathematical Model、Mesh Generation and Boundary Conditions}

The spillway tunnel is $1076.104 \mathrm{~m}$ in length, and the imported bottom elevation is $695 \mathrm{~m}$ high. There is a pressure section before the working gate, which is $526.749 \mathrm{~m}$ long. The maximum operating water head of the working gate is $120 \mathrm{~m}$ high. There is also a sudden enlargement and sudden drop in the working gate room, which is connected to the ventilation hole. The layout of physical model of the spillway tunnel is depicted in Figure 1. In Fig. 1, the gradient of i1 section of the non-pressure section is 0.2 , after which is the i $2=0.09$ standard section, and then the non pressure section of $\mathrm{i} 3=0.07$ 、 $i 4=0.07$

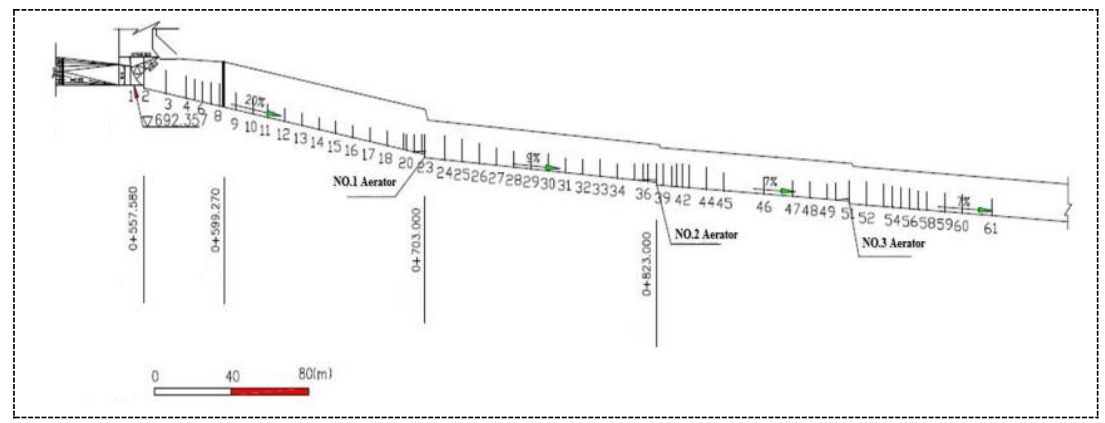

Fig. 1. The layout of physical model of the spillway tunnel

In order to study the hydraulic characteristics of spillway tunnel, turbulent model was used in the mathematical model, and the specific equations of continuity equation and momentum equation can be seen in the literature [9]. Finite volume method was adopted for discrete of equation, the wall function method $[10,12]$ was adopted to solve the model, and PISO method was adopted for coupling of speed and pressure. VOF model was used for the simulation of free surface. In the volume ratio equation, by solving volume ratios of continuous equation of one phase or multi-phases, the interface between the tracking phase is obtained, for instance, the $\mathrm{q}$ phase, the continuous equation is as follows:

$$
\frac{\partial \alpha_{q}}{\partial t}+v \cdot \nabla \alpha_{q}=\frac{S_{\alpha_{q}}}{\rho_{q}}
$$


Where and is volume fraction and density in the q phase, respectively. The default value of is zero.

The volume ratio of main phase is obtained by the following formula

$$
\sum_{q=1}^{n} \alpha_{q}=1
$$

For two phase flows, the density of each calculating unit is:

$$
\rho=\alpha_{2} \rho_{2}+\left(1-\alpha_{2}\right) \rho_{1}
$$

The velocity field results obtained from solving the single momentum equation of the whole area is shared by every phase. Momentum equation depends on properties and achieved from the volume ratio of all phases, and the formula is as follows:

$$
\frac{\partial}{\partial t}(\rho v)+\nabla \cdot(\rho v v)=-\nabla p+\nabla \cdot\left[\mu\left(\nabla v+\nabla v^{T}\right)\right]+\rho g+F
$$

The overall numerical simulation calculation domain of the spillway tunnel is depicted in Fig. 2. The combination of unstructured and structured hexahedral was adopted for simulation of the entirety mesh. Structured mesh was adopted for the reservoir area、 aerators 、 the horseshoe openings and flip bucket; the combination of unstructured and structured mesh was adopted for pressured section and working chamber. Mesh generation diagram of working chamber and parts of ventilation hole is depicted in Fig. 3. In the overall numerical simulation of the spillway tunnel, water flow inlet was set to be speed inlet; ventilation hole and shaft inlet were set to be boundary conditions of pressure inlet; flip bucket outlet and uncovered section were set to be boundary conditions of pressure outlets.

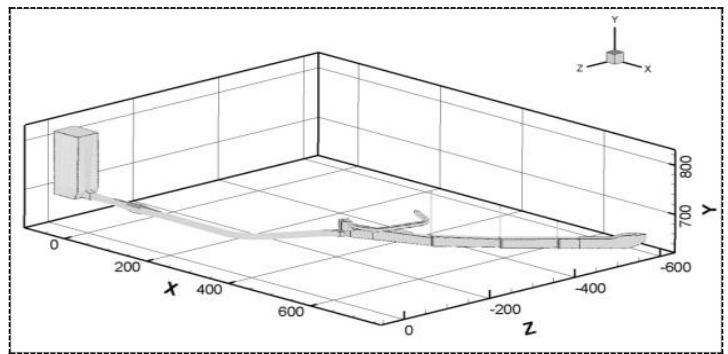

Fig. 2. Numerical. model. calculation domain

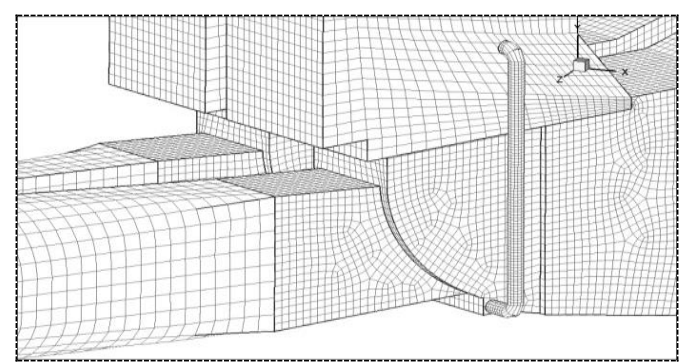


Fig. 3. Mesh generation diagram of working gate with sudden enlargement and sudden drop

\section{Sults and Analysis}

Initializing the flow field before calculation, and assigning the numerical value of the volume fraction of the reservoir water to 1, namely the area is full of water. Water flows from the reservoir after the calculation. When the bulkhead gate is open, filling the front part of the pressure section with water, while the second half part of the spillway tunnel is still full of air. With the time coursing, water flows forward in the form of open channel after the water flows passing through the sudden drop in the working gate, and forming lateral and bottom cavity in the sudden enlargement and sudden drop. Water forms stable cavity after flowing through the aerators in the i1, i2, i3 slope sections. The model is unsteady simulations, so it can comprehensively reflect the flow process of the water, consistent with the actual situation of water flow.

\subsection{Discharge Capacity}

The discharge capacity of the spillway tunnel under the condition of checking water level $(817.99 \mathrm{~m})$ is calculated. The calculating result of the discharge capacity of the spillway tunnel is $3405 \mathrm{~m} 3 / \mathrm{s}$, and the flow coefficient of the tunnel is 0.7126 calculated by the formula of discharge coefficient seen in the literature [6]. While the test value of the discharge capacity is $3315 \mathrm{~m} 3 / \mathrm{s}$, the corresponding flow coefficient is 0.7101 . The difference is $0.35 \%$ between the numerical calculation and the experimental flow coefficient, so the numerical simulation of the discharge capacity accords with the test result.

\subsection{Water Depth}

Cross sectional water depths along the spillway tunnel are shown in table 1 . Table 1 shows that the water depth in both sides of the il slope is lower than that in the middle part, the water depth in the middle part of the i2 slope upstream part is lower than that in both sides. When water flow touches the wall, it will climb along the spillway tunnel. In the i2 slope section, there will appear water crown. In the middle part of i3, i4, the water depth is highly consistent. Empirical formula calculated results listed in the Table 1, too. It shows that the experiment water depth is slightly smaller than the aeration water depth, while the maximum deviations are less than 5\%. So empirical formula can make up for the defects of the VOF model

\subsection{Ventilation Characteristics}

The values of depth of water and the volume of ventilated air in three aerators are listed in Table 2. It shows that the volumes of ventilated air by simulation and empirical formula in NO.1, 3 aerators are more consistent, but that in NO.2 aerator has large deviation. So the results of the volume of ventilated air simulated by VOF model are credible, but we should improve the VOF model to more accurately simulate aerated flow in future 
Table 1 Cross sectional water depths along the spillway tunnel

\begin{tabular}{|c|c|c|c|c|c|c|c|c|}
\hline \multirow{3}{*}{$\begin{array}{c}\text { Pile } \\
\text { number }\end{array}$} & \multicolumn{6}{|c|}{$\begin{array}{c}\text { Water depth } \\
(\mathrm{m})\end{array}$} & \multirow{3}{*}{$\begin{array}{l}\bar{H} \\
(\mathrm{~m})\end{array}$} & \multirow{3}{*}{$\begin{array}{l}h_{b} \\
(\mathrm{~m})\end{array}$} \\
\hline & \multicolumn{2}{|c|}{ Left side } & \multicolumn{2}{|c|}{ Middle part } & \multicolumn{2}{|c|}{ Right side } & & \\
\hline & $\begin{array}{c}\text { Calculated } \\
\text { value }\end{array}$ & $\begin{array}{c}\text { Test } \\
\text { value }\end{array}$ & $\begin{array}{c}\text { Calculated } \\
\text { value }\end{array}$ & $\begin{array}{c}\text { Test } \\
\text { value }\end{array}$ & $\begin{array}{c}\text { Calculated } \\
\text { value }\end{array}$ & $\begin{array}{c}\text { Test } \\
\text { value }\end{array}$ & & \\
\hline $0+621.774$ & 8.89 & 6.43 & 7.22 & 4.56 & 8.75 & 6.97 & 8.29 & 8.64 \\
\hline $0+657.075$ & 5.45 & 5.18 & 9.05 & 7.32 & 8.51 & 5.39 & 7.67 & 7.89 \\
\hline $0+674.726$ & 7.30 & 5.13 & 7.80 & 9.29 & 8.33 & 5.57 & 7.81 & 8.13 \\
\hline $0+722.398$ & 12.20 & 11.62 & 10.76 & 7.14 & 11.12 & 8.83 & 11.36 & 11.76 \\
\hline $0+758.253$ & 10.98 & 7.77 & 10.17 & 5.43 & 9.77 & 8.03 & 10.30 & 10.71 \\
\hline $0+774.281$ & 8.56 & 8.05 & 12.06 & 6.73 & 8.16 & 7.08 & 9.59 & 9.89 \\
\hline $0+794.108$ & 8.96 & 5.85 & 11.52 & 8.29 & 7.43 & 6.53 & 9.30 & 9.78 \\
\hline $0+849.386$ & 11.79 & 8.03 & 8.60 & 8.73 & 11.79 & 7.66 & 10.73 & 11.18 \\
\hline $0+879.014$ & 11.12 & 7.89 & 9.14 & 6.31 & 13.10 & 7.21 & 11.12 & 11.22 \\
\hline $0+902.806$ & 8.96 & 6.89 & 12.69 & 6.25 & 10.58 & 8.32 & 10.74 & 10.96 \\
\hline $0+945.795$ & 12.59 & 7.74 & 12.82 & 8.42 & 10.66 & 8.71 & 12.39 & 12.60 \\
\hline $0+997.419$ & 10.13 & 6.75 & 8.07 & 6.66 & 9.08 & 7.74 & 9.39 & 9.73 \\
\hline
\end{tabular}

Table 2 The.ues of depth of water and the volume of ventilated air in three aerators

\begin{tabular}{|c|c|c|c|c|c|}
\hline Aerator & $\begin{array}{c}\text { Depth of } \\
\text { water } \\
(\mathrm{m})\end{array}$ & $\begin{array}{c}\text { Depth of } \\
\text { aerated flow } \\
(\mathrm{m})\end{array}$ & $\begin{array}{c}\text { Volume of ventilated air } \\
\text { by empirical formula } \\
\left(\mathrm{m}^{3} / \mathrm{s}\right)\end{array}$ & $\begin{array}{c}\text { Volume of ventilated } \\
\text { air by simulation } \\
\left(\mathrm{m}^{3} / \mathrm{s}\right)\end{array}$ & $\begin{array}{c}\text { Difference } \\
\text { value } \\
(\%)\end{array}$ \\
\hline No.1 & 7.82 & 12.02 & 188.61 & 196.51 & $4.19 \%$ \\
\hline No.2 & 7.70 & 11.91 & 213.72 & 190.84 & $-10.71 \%$ \\
\hline No.3 & 7.45 & 11.65 & 228.78 & 217.87 & $-4.77 \%$ \\
\hline
\end{tabular}

\subsection{Pressure Distribution}

Pressure of pressure section of the spillway tunnel is listed in Table 3. It shows that the values are all positive, which indicates the size of the spillway tunnel is adoptable. Pressure in the bottom is decreasing along the flow direction, and pressure in the interior side of turning section is $100 \sim 165 \mathrm{kPa}$ smaller than the one in the lateral side. The pressure value by calculated and the test are more consistent, and the value by calculated is smaller than that by the test

Table 3 Pressure of measuring points in the pressure section

\begin{tabular}{|c|c|c|c|c|c|c|c|}
\hline \multirow{2}{*}{$\begin{array}{c}\text { Pile } \\
\text { number }\end{array}$} & \multirow{2}{*}{ Elevation } & \multicolumn{2}{|c|}{$\begin{array}{c}\text { Pressure } \\
(\mathrm{kPa})\end{array}$} & \multirow{2}{*}{$\begin{array}{c}\text { Pile } \\
\text { number }\end{array}$} & \multirow{2}{*}{ Elevation } & \multicolumn{2}{|c|}{$\begin{array}{c}\text { Pressure } \\
(\mathrm{kPa})\end{array}$} \\
\cline { 3 - 4 } \cline { 6 - 8 } & & $\begin{array}{c}\text { Calculated } \\
\text { value }\end{array}$ & $\begin{array}{c}\text { Test } \\
\text { value }\end{array}$ & & & $\begin{array}{c}\text { Calculated } \\
\text { value }\end{array}$ & $\begin{array}{c}\text { Test } \\
\text { value }\end{array}$ \\
\hline $0+80.500$ & 695.047 & 642.1 & 690.6 & $0+65.240$ & 706.817 & 506.9 & 549.1 \\
\hline $0+107.500$ & 695.015 & 671.7 & 723.1 & $0+101.240$ & 707.002 & 534.8 & 532.9 \\
\hline $0+116.950$ & 694.822 & 647.9 & 696.4 & $0+124.450$ & 706.912 & 535.8 & 576.8 \\
\hline
\end{tabular}




\begin{tabular}{|c|c|c|c|c|c|c|c|}
\hline $0+133.400$ & 693.688 & 642.3 & 683.8 & $0+160.450$ & 706.286 & 462.4 & 498.6 \\
\hline $0+146.900$ & 693.337 & 638.0 & 681.1 & $0+347.411$ & 699.113 & 531.3 & 555.7 \\
\hline $0+173.900$ & 693.112 & 572.3 & 575.9 & $0+360.843$ & 699.037 & 518.2 & 533.1 \\
\hline $0+133.450$ & 700.822 & 599.8 & 637.0 & $0+361.904$ & 699.087 & 352.7 & 398.4 \\
\hline $0+80.500$ & 701.047 & 604.1 & 653.8 & $0+375.867$ & 699.390 & 386.5 & 427.3 \\
\hline $0+119.700$ & 703.5 & 562.8 & 593.1 & $0+119.700$ & 699 & 606.8 & 636.3 \\
\hline
\end{tabular}

\subsection{Wind Speed Distribution}

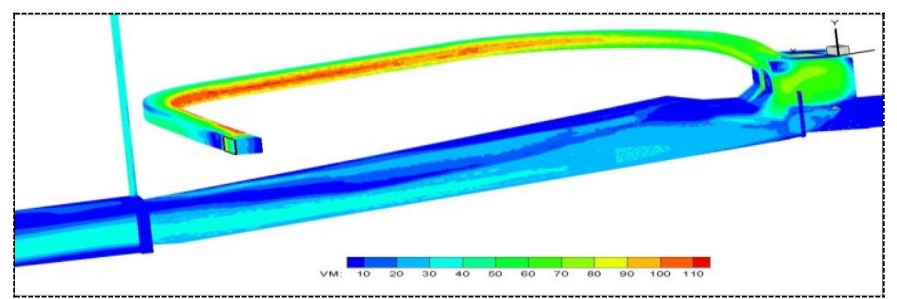

Fig.4. Wind speed distribution of the overall ventilating hole

Wind speed distribution of the overall ventilating hole is depicted in Fig. 4. It shows that the cross-section of ventilating hole is undersize resulting in oversize wind speed in the ventilating hole; because the inlet parallels to the axis of ventilating hole, wind speed distribution is non-uniform near the inlet of ventilating hole and the wind speed on the right side is bigger than that on the left side of overall ventilating hole. Meanwhile, the max value of wind speed is close to $120 \mathrm{~m} / \mathrm{s}$, which can cause loud noise; the layout of two arc segments can well balance wind speed distribution, but bad for air flow; the two straight segments adjust wind speed distribution are all extremely limited

\section{Conclusion}

VOF model and turbulent model were used to carry out three-dimensional calculation of hydraulic characteristic of the spillway tunnel with high head and large discharge on the right band of a hydropower station in China. We get the conclusions as follow:

The numerical simulation of the discharge capacity accords with the experiment results. Empirical formula to converse the calculate value of water depth into aeration water depth can make up for the defects of the VOF model which cannot directly get the aerated water depth of the cross section.

In the pressure section of the spillway tunnel, the values of pressure of emergency gate slot, working gate and the pressing slope, getting from physical model experiment and numerical simulation, are all positive.

At the back of the No.1, 2, 3 aerators, where the values of pressure are negative, forms cavity. At the same time, the results of the volume of ventilated air simulated by VOF model are credible, but the VOF model should be improved to more accurately simulate aerated flow; wind speed distribution is non-uniform near the inlet of ventilating hole and the wind speed on the right side is bigger than that on the left side of overall ventilating hole. 
The layout of two arc segments can well balance wind speed distribution; the two straight segments adjust wind speed distribution are all extremely limited

\section{References}

[1] Guo, J. Zhang, D., Liu, Z.P., et al. Achievements on hydraulic problems in large. s. pillway. tunnel with a high head and large discharge flow and its risk. Analysis. Journal of Hydraulic Engineering. Vol. 37, pp. 1193-1198. (2006)

[2] Luo, Y.Q. 3-D Numerical Simulation on Flood Discharge Tunnel with High Water Head and Free Water Surface. Sichuan University, Sichuan (2006)

[3] Yang, Z.C., Diao, M. J. Deng, J. Numerical simulation study on hydraulic characteristics of high head large discharge spillway tunnel. WATER RESOURCES AND POWER. Vol. 28. pp. 1178-1181. (2010).

[4] Li, G.D. Xu. W.H., Shao. J.B. Numerical simulation of 3D flow at radial gate region with sudden lateral enlargement and bottom drop. ENGINEERING JOURNAL OF WUHAN UNIVERSITY. Vol. 40, pp. 1134-1138. (2007).

[5] SL253 - 2000, Design code for spillway

[6] Deng, J., Xu, W.L., Lei, J. et al. Numerical simulation of hydraulic characteristics of high head spillway tunnel. Journal of Hydraulic Engineering. Vol. 36. pp. 1209-1212, 1218. (2005).

[7] Wang, H.Y. Model test and Turbulence Numerical Simulation on Preventing. Cavitation. Damage of the Dragon-Raise-Head Free Flow Spillway Tunnel with High Head. Sichuan University, Sichuan (2004).

8. Sha, H.F., Wu, S.Q., Chen, Z.W.3D numerical simulation for spillway tunnel. ADVANCES IN WATER SCIENCE. Vol. 17. pp. 1507-1511. (2006).

9. Dai, H. C. Huai. W. X. Wu, Y. L. Xu, W.L. etc. Theories and Applications of Flow Refined Simulation for Hydraulic and Hydropower Engineering, Science Press, Beijing (2006)

10. Versteeg, H.K. Malalasekera. W. An Introduction to Computational Fluid Dynamics: The Finite Volume Method, Wiley, New York (1995)

11. Li, W. Handbook of hydraulic calculations. China waterpower press, Beijing. pp. 304. (2006)

12. Diao. M. J. Numerical Simulation and Experiment Study on Flood Discharge and Energy Dissipation of High Dam with Large Discharge, Sichuan University, chengdu(2004) 